\title{
Muscle Relaxant Preparation
}

National Cancer Institute

\section{Source}

National Cancer Institute. Muscle Relaxant Preparation. NCI Thesaurus. Code C29891.

Synthetic compounds or mixtures with muscle relaxant activity. A muscle relaxant

preparation is used to prevent muscle spasms by inhibiting muscle contractions and to relief pain associated with the spasms. 